\title{
Ultrafast pump/probe diffraction and spectroscopy experiments with FEL radiation: setup development from the soft to the hard X-rays with the aim of studying chemical processes
}

\author{
Ivan Rajkovic, Sebastian Grübel, Wilson Quevedo and Simone Techert* \\ Max Planck Institute for Biophysical Chemistry, Am Fassberg 11, 37077 Göttingen, \\ Germany
}

\begin{abstract}
We developed a multipurpose vacuum chamber which function is to be used in the pump/probe diffraction / scattering and spectroscopy experiments with free electron laser (FEL) radiation. By using a liquid jet setup to deliver the sample into the chamber it is possible to overcome the difficulties coming from the fact that a single shot of the FEL radiation is sufficient to induce irreversible damage to the sample. The continuous refreshment of the sample allows the experiments with the repetition rate of up to the $\mathrm{MHz}$ regime. The liquid jet nozzle size is in the micrometer range. This multipurpose chamber is in particular suited for chemistry and biochemistry experiments in solution.
\end{abstract}

Keywords: FEL, ultrafast, X-ray diffraction, X-ray scattering, X-ray emission spectroscopy, liquid jet

\section{INTRODUCTION}

Scattering experiments with soft X-ray radiation $(1 \mathrm{~nm}-10 \mathrm{~nm})$ are ideal for studying the structure of nanosized objects and for determining the electron density shape of periodic structures of nanoensembles with lattice constants of about $5 \mathrm{~nm}$ to $10 \mathrm{~nm}$ and bigger (periodic self-assembled structures or macromolecular crystals). ${ }^{1}$ Structural studies on such materials are of particular importance for the development of nanoconfined materials with new and extraordinary physical and chemical properties, in biology or in nanomedicine. ${ }^{2}$ Recent developments of highly intense ultrashort soft X-ray radiation generated with the soft X-ray free electron lasers (FLASH, LCLS) ${ }^{3,4}$ allows for new kind of diffraction, spectroscopic or imaging experiments. ${ }^{5-10}$ Extending the X-ray energies into the hard X-ray regime (XFEL,LCLS) will extend these experiments to much broader types of samples. The coupling of an optical femtosecond laser enables the ultrafast timeresolved experiments with X-ray radiation. The optical laser excitation can be used to change the state of matter, to generate structures far away from equilibrium or initiate chemical ${ }^{11,12}$ or biochemical ${ }^{13,14}$ reac- $^{-}$ tions with the advantage of an initial, optically well-defined and coherent excitation of the sample, and the $\mathrm{X}$-ray pulses are then used to probe the excited states and follow their evolution. It is also possible to use the X-ray beam to induce changes in the materials and then probe with the laser pulses to monitor changes in the electro-optical properties. The latest improvements in timing between the optical and the free electron laser pulses achieved the time resolution of better than $10 \mathrm{fs} .{ }^{15}$ With the possibility to insert liquid samples in a liquid jet form into vacuum, ${ }^{16-19} \mathrm{FEL}$ experiments are no more limited to solid and gaseous samples.

Due to the high absorbance of soft X-ray photons by air these experiments require high vacuum conditions. The vacuum chambers have to be big enough to allow connection of all necessary equipment, e.g. sample holders and detectors. At the same time, these chambers should be as small as possible so that the downtime in the operation when they have to be vented and pumped down again is kept minimal. In this work, we present a design of a multipurpose vacuum chamber which can be used for multiple types of pump/probe measurements (X-ray diffraction and emission, optical transmission and reflection) while having a small size.

\footnotetext{
*E-mail: stecher@gwdg.de, Telephone: +49 5512011268
} 


\section{EXPERIMENTAL SETUP}

The experimental setup for the liquid jet experiments consists of a main vacuum chamber with the liquid jet and different X-ray detectors connected to this chamber. Due to the high evaporation rate of liquids inside the vacuum environment it is necessary to ensure that the vacuum conditions remain stable during the experiments and that pressure stays good enough that the setup can be connected to the X-ray source delivery system. For this purpose, at least two differential pumping stages are used to connect the main chamber to the beamline.

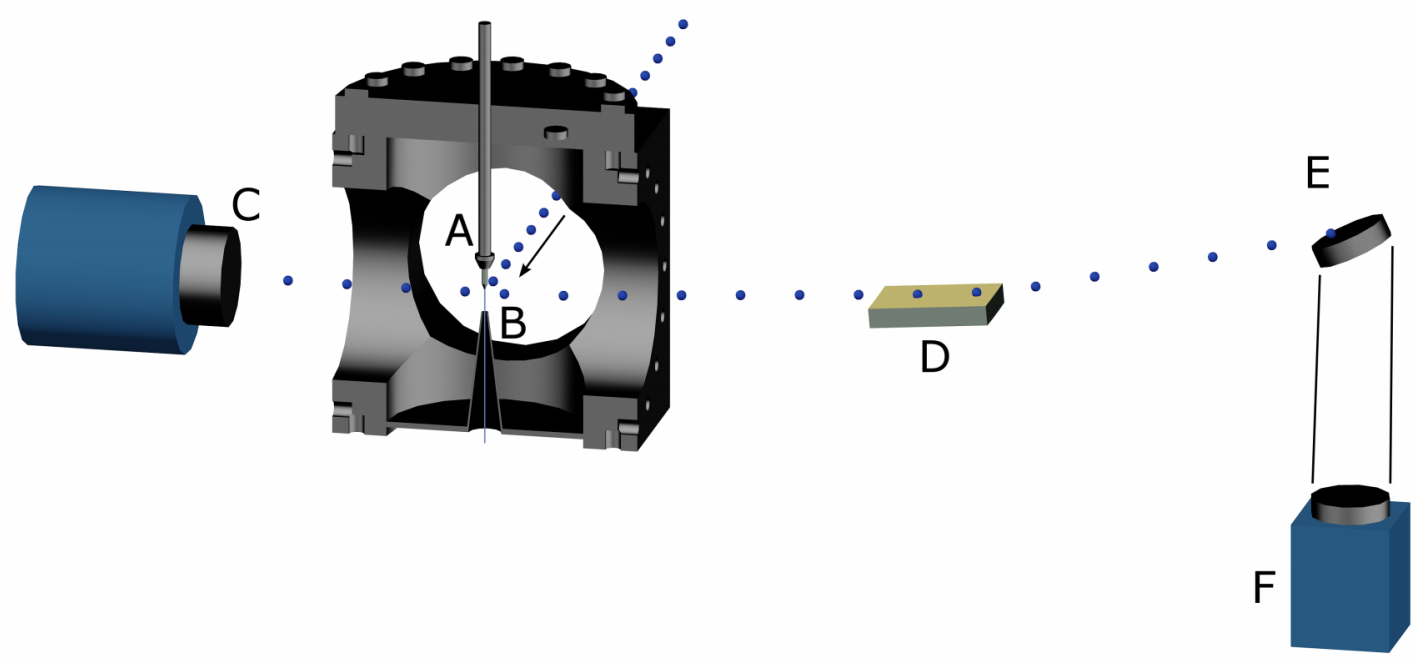

Figure 1. (Color online) Schematic drawing of liquid jet experimental setup. The liquid jet (A) is injected into the vacuum from upper side and enters the skimmer (B). X-rays (blue pulses) are hitting the liquid jet. Scattered X-rays are detected with an X-ray CCD camera (C). Emitted X-rays are dispersed by the grating (D) onto the CsI covered $\mathrm{MCP}$ detector with a phosphorus screen $(\mathrm{E})$, which image is recorded by a CCD camera $(\mathrm{F})$

An HPLC (high performance liquid chromatography) pump system is used for delivering the liquid sample solution into the chamber. It can deliver stable flow rate and achieve high pumping pressure, both of which are needed for obtaining stable liquid jet flow during the experiments. The pump system consists of a three channel degasser followed by a low pressure gradient unit and an HPLC pump. By using the low pressure gradient unit it is possible to mix three different liquids in any ratio from 1 to 100 percent. This is particularly important for experiments where concentration dependent studies of a liquid samples are to be performed. By utilizing an autosampler after the pump, it is possible to insert small volumes of liquids $(10 \mu \mathrm{l}-2 \mathrm{ml})$ directly into the tubing delivering the sample to the jet nozzle, which is extremely useful when working with samples with limited quantity.

Inside the vacuum chamber, liquid sample travels a limited length in the range of a few millimeters before 
interacting with X-rays (Fig 1). The top entrance of a skimmer is placed immediately after the interaction point, minimizing the path that jet travels inside the main vacuum chamber and in that way limiting the evaporation of the liquid sample. After the skimmer the liquid stays frozen inside the cooling trap which is immersed in the liquid nitrogen.

The spectrometer is positioned with 90 degrees in respect to the incident X-rays. For soft X-rays, commercially available spectrometer XES350 from VG Scienta is used ${ }^{20}$ It has three gratings and it can be used for X-rays energies in the range from 20 to $1500 \mathrm{eV}$. The X-rays are detected using an CsI covered dual plate microchannel plate (MCP) detector which is positioned in grazing incident geometry. The signal from the phosphorus screen connected to the MCP detector is then recording using a CCD camera. Usually, one important part of the spectrometer is an entrance slit which collimates the X-rays coming from the sample and in that case it is regarded as the geometrical source of the emitted X-rays. The entrance slit, gratings and the MCP detector have the Rowland circle geometry in order to have the focused X-ray beam on the detector which ensures that the measurements will have the maximal resolution achievable. However, when working with the liquid jet which size is on the scale of few tens of micrometers, the slit can be taken out. In that case the interaction point between the X-rays and the liquid jet is both the real and the geometrical source of the emitted X-rays.

For hard X-rays, the spectrometer with crystal analyzer can be used. ${ }^{21}$ In this case, single crystals of different materials (e.g. silicon or germanium) are used as mirrors so that emitted X-rays are reflected in Bragg geometry onto a X-ray detector.

A X-ray CCD camera is positioned to the opposite side of the spectrometer and it is used to detect the $\mathrm{X}$-rays which are scattered by the sample. Apart from the traditional X-rays CCD cameras, a new type of detector can be used for this purpose, the pnCCD detector. ${ }^{22,23}$ This detector has multiple advantages over X-ray CCD cameras: low noise level, high signal-to-noise ratio, high readout rate and the ability to determine the energy of incoming X-rays with $1 \%$ resolution. Although the energy resolution is not sufficient for this detector to be used as a spectrometer, knowing both the scattering angle and the energy of each individual $\mathrm{X}$-ray can vastly improve the understanding of underlying mechanism responsible for scattering.

Another newly developed X-ray detector suitable for this purpose is Pilatus. ${ }^{24,25}$ Similarly to pnCCD detector, Pilatus also offers high signal-to-noise ratio, no readout noise and fast readout time. However, while pnCCD can detect the soft X-rays or even the near-infrared photons, ${ }^{23}$ Pilatus detector is suitable for detection of hard X-rays only, with the lowest detectable energy of $7 \mathrm{keV}$.

\section{METHODS}

Solving the protein structure is still one of the open questions in science. Although there are some well established techniques which can provide us with enough information to solve the structure, like X-ray diffraction, they usually demand protein crystals which is not always easy to obtain. In order to overcome this problem, we propose to use the liquid solution of proteins or other chemicals as a sample. The advantages of this approach are many, first of which is that crystallization can lead to the distortion of protein structure and, when studying chemical reactions, liquid solutions are the preferred way of providing the reactants. Also, constant problem with crystals is the radiation damage when the probe beam carries enough intensity to induce non-reversible changes to the sample. When using the liquid jet to deliver the sample it is possible to choose the flow rate of the jet in such a way that each probe pulse will interact with the new, refreshed sample volume so that it will not experience any effect which might be triggered by the previous pulse.

There are some disadvantages of this method and they will be addressed here. One of the main obstacles in using a liquid jet for delivering a protein solution is the sample quantity. For most of the proteins the usual availability is on the order of grams or even less. Depending in the jet properties (size, flow rate) and the numbers of photons per second available, the amount of sample solution needed for the experiment can be in tens or even hundreds of milliliters. This is why it is very important to minimize the size of the jet to match the size of the probe pulse so that there will be no unnecessary usage of the sample. Also, knowing 
that XFEL will operate with a $10 \mathrm{~Hz}$ repetition rate, it is possible to synchronize the injection of the sample solution into the liquid jet with the arrival of the X-ray pulses. In that case, the liquid sample will be injected into the chamber for a millisecond so that it arrives to the interaction point simultaneously with the X-ray pulse, and for the next $99 \mathrm{~ms}$ before the next X-ray train the jet will consist of solvent only.

Since the XFEL is going to have up to 3.000 pulses inside on pulse train, with one train being $600 \mu \mathrm{s} \mathrm{long,}{ }^{26}$ it is important to ensure that each X-ray pulse interact with a fresh part of the sample. In order to have a spacing of $20 \mu \mathrm{m}$ between two pulses the jet would have to have speed of $100 \mathrm{~m} / \mathrm{s}$. For a liquid jet with a diameter of $20 \mu \mathrm{m}$ that would mean that the flow rate should be $1.9 \mathrm{ml} / \mathrm{min}$, which is easily achievable.

One way of minimizing the amount of liquid needed is to choose the size of the liquid jet depending on the absorption depth of the X-rays and their focus size. Usually the focus size is in sub $10 \mu \mathrm{m}$ range while the absorption depth for soft X-rays is considerably smaller, from a few hundreds of nanometers up to a micrometer. By crafting the liquid jet cross-section to be, instead of circular, elliptical with the dimensions corresponding the diameter and absorption length of the X-rays, unnecessary waste of the sample material could be avoided. Also, by minimizing the liquid volume inside the chamber it would be possible to achieve better and more stable vacuum conditions during the experiments.

One of the difficulties when working with the low concentrated solutions is that the signal coming from the sample can be very week. In order to probe the chemical reactions of molecules in solution the molarity of the solution should not be higher that few tens of millimole per liter. In that situation, most of the X-rays will be scattered or absorbed by solvent before coming to the sample molecule which should be investigated. This leads not only to the increased measurement time needed to obtain sufficient signal but also to the lower signal-to-noise ratio. The increase of the noise signal at the detector can come either from the X-rays being scattered from the solvent or from the thermal noise of the detector. During first X-ray emission spectrometry measurements at the BESSY synchrotron, the average count rate for $10 \mathrm{mMol} / \mathrm{l}$ solution was 15 counts/s, where only one quarter of total count rate was coming from the emitted X-rays and the rest was the background noise.

Having that in mind, it is straightforward to propose two different ways of minimizing noise thus improving signal-to-noise ratio: first would be to increase the signal count by using new, more intense X-ray sources such as FELs, or using the detectors with lower background and read-out noise.

One of the most important advantage of free electron laser in respect to the synchrotrons, together with ultrafast pulse duration, is the high number of X-ray photons per pulse. The numbers of soft X-ray photons in one pulse at LCLS free electron laser $\left(\sim 10^{12}-10^{13}\right)$ is in the same order of magnitude as number of photons per second at the $3^{r d}$ generation synchrotron sources. ${ }^{4}$ Keeping in mind that the LCLS can work with the repetition rate of 60 or $120 \mathrm{~Hz}$, it is evident that by using FEL the time needed to record one emission spectra can be up to 100 times faster then when performing the same experiment at the synchrotrons; instead of 15 minutes, the measurement will be done in 10 seconds. This way it is also possible to minimize the noise signal and gain the usable emission signal from the solutions with sample concentration of even less than $1 \mathrm{mMol} / 1$.

\section{SUMMARY}

We have built a compact and easily extendable vacuum chamber for versatile experiments with FEL radiation. Its small size is especially convenient for fast allocating to different experimental facilities. Although its primal function is to be used in experiments involving FEL radiation, it can be used for any diffraction or emission spectroscopy experiments with high vacuum requirement. The jet system provide the means for serial experiments, like serial diffraction and serial spectroscopy, where rapid exchange of samples is required.

\section{ACKNOWLEDGMENTS}

This work was supported by SFB 602 and SFB 755 of the Deutsche Forschungsgemeinschaft. Furthermore, S. T. is grateful to the DFG (TE347, 1-3), Aventis Foundation, Fonds of the Chemical Industry and EU-FLASH MC-8041. Authors would like to thank the Max Planck Advanced Study Group for their continuous support. 


\section{REFERENCES}

[1] Guinier, A., [X-ray diffraction in crystals, imperfect crystals, and amorphous bodies], Dover Publications, New York (1963).

[2] Ramos, A. S. F. and Techert, S., "Influence of the water structure on the acetylcholinesterase efficiency.," Biophys. J. 89(3), 1990-2003 (2005).

[3] Saldin, E., Schneidmiller, E., and Yurkov, M., [The physics of free electron lasers], Springer Verlag (2000).

[4] Ackermann, W., Asova, G., Ayvazyan, V., Azima, A., Baboi, N., Baehr, J., Balandin, V., Beutner, B., Brandt, A., Bolzmann, A., Brinkmann, R., Brovko, O. I., Castellano, M., Castro, P., Catani, L., Chiadroni, E., Choroba, S., Cianchi, A., Costello, J. T., Cubaynes, D., Dardis, J., Decking, W., DelsimHashemi, H., Delserieys, A., Pirro, G. D., Dohlus, M., Duesterer, S., Eckhardt, A., Edwards, H. T., Faatz, B., Feldhaus, J., Floettmann, K., Frisch, J., Froehlich, L., Garvey, T., Gensch, U., Gerth, C., Goerler, M., Golubeva, N., Grabosch, H.-J., Grecki, M., Grimm, O., Hacker, K., Hahn, U., Han, J. H., Honkavaara, K., Hott, T., Huening, M., Ivanisenko, Y., Jaeschke, E., Jalmuzna, W., Jezynski, T., Kammering, R., Katalev, V., Kavanagh, K., Kennedy, E. T., Khodyachykh, S., Klose, K., Kocharyan, V., Koerfer, M., Kollewe, M., Koprek, W., Korepanov, S., Kostin, D., Krassilnikov, M., Kube, G., Kuhlmann, M., Lewis, C. L. S., Lilje, L., Limberg, T., Lipka, D., Loehl, F., Luna, H., Luong, M., Martins, M., Meyer, M., Michelato, P., Miltchev, V., Moeller, W. D., Monaco, L., Mueller, W. F. O., Napieralski, O., Napoly, O., Nicolosi, P., Noelle, D., Nunez, T., Oppelt, A., Pagani, C., Paparella, R., Pchalek, N., Pedregosa-Gutierrez, J., Petersen, B., Petrosyan, B., Petrosyan, G., Petrosyan, L., Pflueger, J., Ploenjes, E., Poletto, L., Pozniak, K., Prat, E., Proch, D., Pucyk, P., Radcliffe, P., Redlin, H., Rehlich, K., Richter, M., Roehrs, M., Roensch, J., Romaniuk, R., Ross, M., Rossbach, J., Rybnikov, V., Sachwitz, M., Saldin, E. L., Sandner, W., Schlarb, H., Schmidt, B., Schmitz, M., Schmueser, P., Schneider, J. R., Schneidmiller, E. A., Schnepp, S., Schreiber, S., Seidel, M., Sertore, D., Shabunov, A. V., Simon, C., Simrock, S., Sombrowski, E., Sorokin, A. A., Spanknebel, P., Spesyvtsev, R., Staykov, L., Steffen, B., Stephan, F., Stulle, F., Thom, H., Tiedtke, K., Tischer, M., Toleikis, S., Treusch, R., Trines, D., Tsakov, I., Vogel, E., Weiland, T., Weise, H., Wellhoefer, M., Wendt, M., Will, I., Winter, A., Wittenburg, K., Wurth, W., Yeates, P., Yurkov, M. V., Zagorodnov, I., and Zapfe, K., "Operation of a free-electron laser from the extreme ultraviolet to the water window," Nature 1(6), 336-342 (2007).

[5] Chapman, H., Barty, A., Bogan, M., Boutet, S., Frank, M., Hau-Riege, S., Marchesini, S., Woods, B., Bajt, S., Benner, W., et al., "Femtosecond diffractive imaging with a soft-X-ray free-electron laser," Nature Physics 2(12), 839-843 (2006).

[6] Coppens, P., Novozhilova, I., and Kovalevsky, A., "Photoinduced linkage isomers of transition-metal nitrosyl compounds and related complexes," Chemical reviews 102(4), 861-884 (2002).

[7] Gahl, C., Azima, A., Beye, M., Deppe, M., Döbrich, K., Hasslinger, U., Hennies, F., Melnikov, A., Nagasono, M., Pietzsch, A., Wolf, M., Wurth, W., and Foehlisch, A., "A femtosecond X-ray/optical cross-correlator," Nature Photonics 2(3), 165-169 (2008).

[8] Hau-Riege, S. P., London, R. A., Chapman, H. N., Szoke, A., and Timneanu, N., "Encapsulation and diffraction-pattern-correction methods to reduce the effect of damage in x-ray diffraction imaging of single biological molecules.," Phys. Rev. Lett. 98(19), 198302 (2007).

[9] Chapman, H. N., Fromme, P., Barty, A., White, T. A., Kirian, R. A., Aquila, A., Hunter, M. S., Schulz, J., DePonte, D. P., Weierstall, U., Doak, R. B., Maia, F. R. N. C., Martin, A. V., Schlichting, I., Lomb, L., Coppola, N., Shoeman, R. L., Epp, S. W., Hartmann, R., Rolles, D., Rudenko, A., Foucar, L., Kimmel, N., Weidenspointner, G., Holl, P., Liang, M., Barthelmess, M., Caleman, C., Boutet, S., Bogan, M. J., Krzywinski, J., Bostedt, C., Bajt, S., Gumprecht, L., Rudek, B., Erk, B., Schmidt, C., Hömke, A., Reich, C., Pietschner, D., Strüder, L., Hauser, G., Gorke, H., Ullrich, J., Herrmann, S., Schaller, G., Schopper, F., Soltau, H., Kühnel, K.-U., Messerschmidt, M., Bozek, J. D., Hau-Riege, S. P., Frank, M., Hampton, C. Y., Sierra, R. G., Starodub, D., Williams, G. J., Hajdu, J., Timneanu, N., Seibert, M. M., Andreasson, J., Rocker, A., Jönsson, O., Svenda, M., Stern, S., Nass, K., Andritschke, R., Schröter, C.D., Krasniqi, F., Bott, M., Schmidt, K. E., Wang, X., Grotjohann, I., Holton, J. M., Barends, T. R. M., Neutze, R., Marchesini, S., Fromme, R., Schorb, S., Rupp, D., Adolph, M., Gorkhover, T., Andersson, 
I., Hirsemann, H., Potdevin, G., Graafsma, H., Nilsson, B., and Spence, J. C. H., "Femtosecond X-ray protein nanocrystallography.," Nature 470(7332), 73-7 (2011).

[10] Seibert, M. M., Ekeberg, T., Maia, F. R. N. C., Svenda, M., Andreasson, J., Jönsson, O., Odić, D., Iwan, B., Rocker, A., Westphal, D., Hantke, M., DePonte, D. P., Barty, A., Schulz, J., Gumprecht, L., Coppola, N., Aquila, A., Liang, M., White, T. A., Martin, A., Caleman, C., Stern, S., Abergel, C., Seltzer, V., Claverie, J.-M., Bostedt, C., Bozek, J. D., Boutet, S., Miahnahri, A. A., Messerschmidt, M., Krzywinski, J., Williams, G., Hodgson, K. O., Bogan, M. J., Hampton, C. Y., Sierra, R. G., Starodub, D., Andersson, I., Bajt, S., Barthelmess, M., Spence, J. C. H., Fromme, P., Weierstall, U., Kirian, R., Hunter, M., Doak, R. B., Marchesini, S., Hau-Riege, S. P., Frank, M., Shoeman, R. L., Lomb, L., Epp, S. W., Hartmann, R., Rolles, D., Rudenko, A., Schmidt, C., Foucar, L., Kimmel, N., Holl, P., Rudek, B., Erk, B., Hömke, A., Reich, C., Pietschner, D., Weidenspointner, G., Strüder, L., Hauser, G., Gorke, H., Ullrich, J., Schlichting, I., Herrmann, S., Schaller, G., Schopper, F., Soltau, H., Kühnel, K.-U., Andritschke, R., Schröter, C.-D., Krasniqi, F., Bott, M., Schorb, S., Rupp, D., Adolph, M., Gorkhover, T., Hirsemann, H., Potdevin, G., Graafsma, H., Nilsson, B., Chapman, H. N., and Hajdu, J., "Single mimivirus particles intercepted and imaged with an X-ray laser.," Nature 470(7332), 78-81 (2011).

[11] Busse, G., Tschentscher, T., Plech, A., Wulff, M., Frederichs, B., and Techert, S., "First investigations of the kinetics of the topochemical reaction of p-formyl-trans-cinnamic acid by time-resolved X-ray diffraction," Faraday Discussions 122, 105-117 (2003).

[12] Jung, A., Domratcheva, T., Tarutina, M., Wu, Q., Ko, W., Shoeman, R., Gomelsky, M., Gardner, K., and Schlichting, I., "Structure of a bacterial BLUF photoreceptor: insights into blue light-mediated signal transduction," Proceedings of the National Academy of Sciences of the United States of America 102(35), $12350(2005)$.

[13] Collet, E., Lemée-Cailleau, M.-H., Cointe, M. B.-L., Cailleau, H., Wulff, M., Luty, T., Koshihara, S.-Y., Meyer, M., Toupet, L., Rabiller, P., and Techert, S., "Laser-induced ferroelectric structural order in an organic charge-transfer crystal.," Science 300(5619), 612-5 (2003).

[14] Yang, X., Stojković, E., Kuk, J., and Moffat, K., "Crystal structure of the chromophore binding domain of an unusual bacteriophytochrome, RpBphP3, reveals residues that modulate photoconversion," Proceedings of the National Academy of Sciences 104(30), 12571 (2007).

[15] Tavella, F., Stojanovic, N., Geloni, G., and Gensch, M., "Few-femtosecond timing at fourth-generation x-ray light sources," Nat Photon 5(3), 162-165 (2011).

[16] Charvat, A., Lugovoj, E., Faubel, M., and Abel, B., "Analytical laser induced liquid beam desorption mass spectrometry of protonated amino acids and their non-covalently bound aggregates," Eur. Phys. J. D 20(3), 573-582 (2002).

[17] Charvat, A., Lugovoj, E., Faubel, M., and Abel, B., "New design for a time-of-flight mass spectrometer with a liquid beam laser desorption ion source for the analysis of biomolecules," Review of Scientific Instruments 75(5), 1209-1218 (2004).

[18] Winter, B., Aziz, E. F., Hergenhahn, U., Faubel, M., and Hertel, I. V., "Hydrogen bonds in liquid water studied by photoelectron spectroscopy.," J Chem Phys 126, 124504 (Mar. 2007).

[19] Weber, R., Winter, B., Schmidt, P. M., Widdra, W., Hertel, I. V., Dittmar, M., and Faubel, M., "Photoemission from aqueous alkali-metaliodide salt solutions using euv synchrotron radiation," The Journal of Physical Chemistry B 108(15), 4729-4736 (2004).

[20] Nordgren, J., Bray, G., Cramm, S., Nyholm, R., Rubensson, J.-E., and Wassdahl, N., "Soft x-ray emission spectroscopy using monochromatized synchrotron radiation (invited)," Review of Scientific Instruments 60(7), 1690-1696 (1989).

[21] Glatzel, P., Sikora, M., Smolentsev, G., and Fernndez-Garca, M., "Hard x-ray photon-in photon-out spectroscopy," Catalysis Today 145(3-4), 294 - 299 (2009).

[22] Leitenberger, W., Hartmann, R., Pietsch, U., Andritschke, R., Starke, I., and Strüder, L., "Application of a pnCCD in X-ray diffraction: a three-dimensional X-ray detector," Journal of Synchrotron Radiation 15, 449-457 (Sep 2008).

[23] Meidinger, N., Andritschke, R., Hartmann, R., Herrmann, S., Holl, P., Lutz, G., and Strder, L., "pnccd for photon detection from near-infrared to x-rays," Nuclear Instruments and Methods in Physics Research Section A: Accelerators, Spectrometers, Detectors and Associated Equipment 565(1), 251 - 257 (2006). 
[24] Eikenberry, E. F., Brnnimann, C., Hlsen, G., Toyokawa, H., Horisberger, R., Schmitt, B., Schulze-Briese, C., and Tomizaki, T., "Pilatus: a two-dimensional x-ray detector for macromolecular crystallography," Nuclear Instruments and Methods in Physics Research Section A: Accelerators, Spectrometers, Detectors and Associated Equipment 501(1), 260 - 266 (2003).

[25] Henrich, B., Bergamaschi, A., Broennimann, C., Dinapoli, R., Eikenberry, E., Johnson, I., Kobas, M., Kraft, P., Mozzanica, A., and Schmitt, B., "Pilatus: A single photon counting pixel detector for x-ray applications," Nuclear Instruments and Methods in Physics Research Section A: Accelerators, Spectrometers, Detectors and Associated Equipment 607(1), 247 - 249 (2009).

[26] "The technical design report of the european xfel <http://xfel.desy.de/tdr/tdr $>$." 